\title{
Prognostic factors for breast cancer squamous cell carcinoma and nomogram development for prediction: population-based research
}

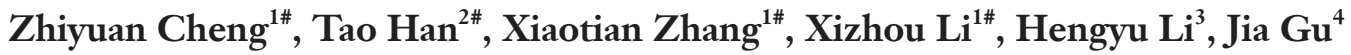 \\ ${ }^{1}$ College of Basic Medical Sciences, Navy Medical University, Shanghai 200433, China; ${ }^{2}$ Department of Oncology, General Hospital of Northern \\ Theater Command, Shenyang, Liaoning 110011, China; ${ }^{3}$ Department of Thyroid and Breast Surgery, Changhai Hospital, Navy Medical University, \\ Shanghai 200433, China; ${ }^{4}$ Department of Otolaryngology-Head and Neck Surgery, The First Affiliated Hospital of China Medical University, \\ Shenyang 110001, China \\ Contributions: (I) Conception and design: Z Cheng, H Li; (II) Administrative support: H Li; (III) Provision of study materials or patients: J Gu; (IV) \\ Collection and assembly of data: Z Cheng, T Han; (V) Data analysis and interpretation: X Zhang; (VI) Manuscript writing: All authors; (VII) Final \\ approval of manuscript: All authors. \\ "These authors contributed equally to this work. \\ Correspondence to: Jia Gu. Department of Otolaryngology-Head and Neck Surgery, The First Affiliated Hospital of China Medical University, \\ Shenyang 110001, China. Email: gujia19840128@aliyun.com; Hengyu Li. Department of Thyroid and Breast Surgery, Changhai Hospital, Navy \\ Medical University, Shanghai 200433, China. Email: drlhy@foxmail.com.
}

Background: To investigate the prognostic survival factors of breast squamous cell carcinoma (BSqCC) and develop a comprehensive nomogram for predicting the survival of breast cancer squamous cell carcinoma.

Methods: Data were obtained from the Surveillance, Epidemiology, and End Results (SEER) database to identify patients diagnosed with BSqCC from 1973 to 2015. The data was obtained using SEER Stat 8.3.4 software, collated, and analyzed by Excel 2016 software and SPSS (v25.0). Kaplan-Meier curves were used for survival analysis. The variables obtained by univariate analysis were introduced into the Cox proportional hazard model for multivariate analysis. The risk factors affecting the prognosis of BSqCC were obtained. $\mathrm{P}<0.05$ was considered statistically significant. The independent prognostic factors of $\mathrm{BSqCC}$ were integrated and used to construct nomograms.

Results: A total of 739 patients with BSqCC was included. The median age of diagnosis was 66 years. In most cases, the expression of estrogen receptor (ER), progesterone receptor (PR), and human epidermal growth factor receptor 2 (HER2) was negative. One-third of the cases underwent breast-conserving surgery, and more than half of the cases underwent mastectomy (unilateral or bilateral). The 1-year survival rate was $81.2 \%$, the 3 -year survival rate was $62.9 \%$, the 5 -year survival rate was $54.4 \%$, and the 10 -year survival rate was $41.4 \%$. Age $\left(\chi^{2}=71.050, \mathrm{P}<0.001\right)$, marital status $\left(\chi^{2}=37.560, \mathrm{P}<0.001\right)$, tumor size $\left(\chi^{2}=27.931, \mathrm{P}<0.001\right)$, surgical procedure $\left(\chi^{2}=74.185, \mathrm{P}<0.001\right)$, the number of positive lymph nodes $\left(\chi^{2}=38.542, \mathrm{P}<0.001\right)$, and the primary site $\left(\chi^{2}=59.217, \mathrm{P}<0.001\right)$ were significantly correlated with patient survival time. Among them, marital status (HR: 0.502, 95\% CI: 0.318-0.794), age (HR: 2.186, 95\% CI: 1.234-3.875), surgical procedure (HR: 1.03, 95\% CI: 1.01-1.051), tumor size (HR: 1.505, 95\% CI: 1.083-2.091) and the number of positive lymph nodes (HR: 1.277, 95\% CI: 1.087-1.499) were independent risk factors for the survival of BSqCC. Five independent prognostic factors were then integrated for the construction of nomograms.

Conclusions: BSqCC was a malignant tumor with a low survival rate. Age of onset was typically at an older age; mostly middle-aged and seniors. Marital status, age, surgical procedure, tumor size, and several positive lymph nodes were independent predictors of patient survival. At the same time, we developed a prognostic nomogram with excellent discrimination for breast cancer squamous cell carcinoma; therefore, it could help clinicians make decisions on a personal basis. 
Keywords: Breast squamous cell carcinoma (BSqCC); nomogram; prognosis analysis; the Surveillance, Epidemiology, and End Results (SEER) database

Submitted Jul 14, 2019. Accepted for publication Sep 03, 2019.

doi: $10.21037 /$ tcr.2019.09.13

View this article at: http://dx.doi.org/10.21037/tcr.2019.09.13

\section{Introduction}

Breast squamous cell carcinoma (BSqCC) is a rare form of breast cancer and is highly malignant. It is defined by the World Health Organization (WHO) as "a breast carcinoma entirely composed of metaplastic squamous cells that may be keratinizing, nonkeratinizing, or spindled; neither derived from the overlying skin nor representing metastases from other sites." Its exact origin is not clear yet, and it is thought to be caused by chronic inflammation, breast abscess, fibroadenomas, and cysts implant (1-3). Clinically, is very rare, mostly found in older women, often presents as a cystic solid or solid mass. The mass is large, proliferates, and less axillary lymph node metastasis (10-30\%) (4,5). Imaging examinations such as ultrasound and molybdenum target imaging are not specific, so they are easily misdiagnosed as breast abscess, breast cyst, or breast phyllodes tumor.

The incidence of $\mathrm{BSqCC}$ accounts for $0.1 \%$ of all primary breast cancers $(6,7)$. This has made it challenging to study epidemiological characteristics. Most epidemiological studies are limited by the rare cases, except for the report of Yadav et al. (8) with a large amount of data, most studies are limited to reports in a single case (9-12). The surveillance, epidemiology, and end results (SEER) database brings together data from multiple medical centers in the United States, providing a sufficient sample size of rare cancers for epidemiological studies. This study used the SEER database to explore the risk factors affecting the survival of $\mathrm{BSqCC}$ and further establish a predictive nomogram, so as to provide a basis for the design of $\mathrm{BSqCC}$ treatment and achieve individualized treatment.

\section{Methods}

\section{Source}

Patients who were diagnosed with BSqCC from 1973 to 2015 were included in the SEER database by SEER Stat software (the surveillance, epidemiology, and end results program institute SEER*State software, version 8.3.4).
Since any information in the SEER database does not require the patient's explicit consent, it is not subject to the ethical approval requirements of the institutional review board.

\section{Patient screening}

Inclusion criteria: (I) patients with pathological diagnosis of BSqCC from 1973 to 2015; (II) follow-up information including diagnosis of age, race, lateral position, primary site, tumor grade, size, 7 th American Cancer Joint Committee (AJCC) tumor staging system, positive regional lymph node number, marital status and other clinical pathological information; (III) histological type is squamous cell carcinoma, large cell keratinizing variant, spindle cell variant, or acantholytic variant. Exclusion criteria: (I) squamous metaplasia of breast cancer cases; (II) benign tumors; (III) cases with unknown survival time; (IV) BSqCC is not the first primary cancer; (V) cases of death within 30 days. A total of 739 patients with BSqCC who met the criteria were screened and collected, and the seventh edition of the UICC/AJCC TNM staging system was used to stage the cases.

\section{Statistical methods}

The database data was obtained by SEER Stat 8.3.4 software, sorted by Excel 2016 software and analyzed by SPSS (v25.0). The Kaplan-Meier curve was drawn for survival analysis, and the variables with univariate analysis were introduced into the Cox proportional hazards model was analyzed by multivariate analysis, to determine the risk factors affecting the prognosis of $\mathrm{BSqCC}$. $\mathrm{P}<0.05$ was considered statistically significant.

\section{Results}

\section{Demographics, tumor characteristics, and treatment}

A total of $739 \mathrm{BSqCC}$ patients were diagnosed during the 
study. Most patients were white, and the median age was 66 (range: 24 to $85+$ years). Studies have shown that the median age of $\mathrm{BSqCC}$ patients is 60 to 70 years old (13). This was consistent with our research. The median tumor size was $3.9 \mathrm{~cm}$, and most tumors had T2 stage at the time of diagnosis. In most cases, there was no lymph node metastasis, and the expression of estrogen receptor (ER), progesterone receptor $(\mathrm{PR})$ and human epidermal growth factor receptor 2 (HER2) was negative (Table 1). Ninetyone of 133 patients with complete immunohistochemical information had triple negative breast cancer.

\section{Univariate analysis of prognostic factors}

According to the survival rate statistics, 739 patients with $\mathrm{BSqCC}$ were included in the study. The overall survival rate was $40.5 \%$, the 1 -year survival rate was $81.2 \%$, the 3 -year survival rate was $62.9 \%$, the 5 -year survival rate was $54.4 \%$, and the 10 -year survival rate was $41.4 \%$. Excluding patients with incomplete single factor data: marital status (694 cases), age (739 cases), gender ( 739 cases), race ( 734 cases), ER (277 cases), HER2 (132 cases), PR (277 cases), tumor size (325 cases), histological grade (546 cases), primary site (739 cases), laterality (731 cases), surgical procedure (529 cases), and number of positive lymph nodes (425 cases).

Age $\left(\chi^{2}=71.050, \mathrm{P}<0.001\right)$, marital status $\left(\chi^{2}=37.560\right.$, $\mathrm{P}<0.001)$, tumor size $\left(\chi^{2}=27.931, \mathrm{P}<0.001\right)$, surgical procedure $\left(\chi^{2}=74.185, \mathrm{P}<0.001\right)$, the number of positive lymph nodes $\left(\chi^{2}=38.542, \mathrm{P}<0.001\right)$, and the primary site $\left(\chi^{2}=59.217, \mathrm{P}<0.001\right)$ was significantly correlated with patient survival time. Remarkably, whether ER, PR, and HER2 were positively had a weak correlation with $\mathrm{BSqCC}$ survival.

Survival status of $\mathrm{BSqCC}$ patients in three age groups was inversely proportional to age, and patients under 39 years of age were the best (mean survival: 345.731 months, $95 \%$ CI: 262.008-429.455 months). Prognosis survival was not optimistic for patients older than 85 years (mean survival period: 40.29 months, 95\% CI: 31.503-49.077 months) (Figure 1).

The prognosis of the married group (mean survival: 199.561 months, 95\% CI: 172.444-226.678 months) was better than that of the unmarried group (mean survival: 120.861 months, 95\% CI: 101.318-140.404 months) (Figure 2).

Prognosis of patients with tumor size $>5 \mathrm{~cm}$ was the worst (mean survival: 53.947 months, 95\% CI: $41.654-$ 66.241 months) (Figure 3).

The survival time of different surgical procedures were quite different (preservation surgery $v s$. resection $v s$. modified radical surgery or radical surgery; average survival: 131.909 vs. 101.025 vs. 91.185 months; 95\% CI: 117.511146.306 vs. 79.971-122.080 vs. 78.389-103.981 months), but significantly better than nonsurgical patients (average survival: 41.227 months, $95 \%$ CI: $26.872-55.582$ months) (Figure 4).

Survival of patients without positive lymph nodes (mean survival: 180.936 months, $95 \%$ CI: 162.010-199.862 months) were superior to patients with positive lymph nodes (Figure 5).

Because the upper-inner, lower-inner, upper-outer and lower-outer quadrants had not much difference, they were merged into the four quadrants of the breast to facilitate the display of the chart (Figure 6).

\section{Report on negative results}

This study was based on survival analysis of 739 real events, The survival difference of race $\left(\chi^{2}=8.086, P=0.018\right)$, gender $\left(\chi^{2}=0.006, \mathrm{P}=0.939\right)$, laterality $\left(\chi^{2}=3.401, \mathrm{P}=0.183\right), \mathrm{ER}$ $\left(\chi^{2}=0.644, \mathrm{P}=0.422\right), \mathrm{PR}\left(\chi^{2}=0.175, \mathrm{P}=0.676\right), \mathrm{HER} 2\left(\chi^{2}=0.090\right.$, $\mathrm{P}=0.764)$, and histological grade $\left(\chi^{2}=0.701, \mathrm{P}=0.873\right)$, were small and had no statistical difference. It was worth noting that gender, ER, PR, and HER2 had no statistical difference in the prognosis of breast cancer squamous cell carcinoma, which was consistent with clinical experience.

\section{Multivariate analysis prognostic factors}

The factors obtained by univariate analysis were introduced into the Cox proportional hazards model for multivariate analysis.

Marital status (HR: 0.502, 95\% CI: 0.318-0.794), age (HR: $2.186,95 \%$ CI: 1.234-3.875), surgical procedure (HR: 1.03, 95\% CI: 1.01-1.051), tumor size (HR: 1.505 , 95\% CI: 1.083-2.091) and the number of positive lymph nodes (HR: 1.277, 95\% CI: $1.087-1.499)$ were independent risk factors affecting the survival of $\mathrm{BSqCC}$ (Table 2).

\section{Prediction model nomogram development and verification}

Nomogram was constructed based on the result of multivariate analyses and the accelerated failure time model. A weighted total score calculated from each variable was used to estimate the 1-, 3-, and 10-year overall survival prediction (Figure 7). Internally validation was done by discrimination and calibration method. C-index was calculated as 0.777 , which indicated excellent discrimination of the nomogram. 
Table 1 Single factors analysis of BSqCC

\begin{tabular}{|c|c|c|c|c|c|c|}
\hline Independent risk factors & \multicolumn{2}{|c|}{ Number of cases } & $\begin{array}{l}\text { Average survival } \\
\text { (month) }\end{array}$ & 95\% Cl (month) & \multicolumn{2}{|c|}{ Single factor analysis } \\
\hline Age & & & & & 71.050 & $<0.001$ \\
\hline$<39$ & 35 & 4.74 & 345.731 & $262.008-429.455$ & & \\
\hline $40-85$ & 621 & 84.03 & 155.921 & $138.560-193.282$ & & \\
\hline$>85$ & 83 & 11.23 & 40.29 & $31.503-49.077$ & & \\
\hline Married statue & & & & & 37.560 & $<0.001$ \\
\hline Married & 308 & 44.38 & 199.561 & $172.444-226.678$ & & \\
\hline Not married & 386 & 55.62 & 120.861 & $101.318-140.404$ & & \\
\hline Overall & 694 & 100.00 & 156.455 & $139.450-173.460$ & & \\
\hline $2-5$ & 139 & 42.77 & 84.789 & $73.815-95.763$ & & \\
\hline$>5$ & 109 & 33.54 & 53.947 & $41.654-66.241$ & & \\
\hline Overall & 325 & 100.00 & 77.709 & $70.416-85.001$ & & \\
\hline Surgery & & & & & 74.185 & $<0.001$ \\
\hline No surgery & 83 & 15.69 & 41.227 & $26.872-55.582$ & & \\
\hline $\begin{array}{l}\text { Breast-conserving or -preserving } \\
\text { surgery }\end{array}$ & 177 & 33.46 & 131.909 & $117.511-146.306$ & & \\
\hline $\begin{array}{l}\text { Total (simple) mastectomy without } \\
\text { an axillary dissection }\end{array}$ & 86 & 16.26 & 101.025 & $79.971-122.080$ & & \\
\hline $1-3$ & 81 & 19.06 & 102.215 & $78.561-125.868$ & & \\
\hline $4-9$ & 28 & 6.59 & 57.18 & $26.622-87.738$ & & \\
\hline$\geq 10$ & 10 & 2.35 & 60.633 & $20.577-100.690$ & & \\
\hline Overall & 425 & 100.00 & 160.599 & $144.286-176.913$ & & \\
\hline Primary site & & & & & 59.217 & $<0.001$ \\
\hline Nipple & 27 & 3.65 & 182.643 & $116.316-248.970$ & & \\
\hline Center & 43 & 5.82 & 70.073 & $46.155-93.991$ & & \\
\hline Upper-inner & 49 & 6.63 & 250.651 & $186.809-314.493$ & & \\
\hline Lower-inner & 28 & 3.79 & 179.069 & $106.870-251.269$ & & \\
\hline Upper-outer & 178 & 24.09 & 175.574 & $141.870-209.278$ & & \\
\hline Lower-outer & 53 & 7.17 & 168.544 & $126.651-210.437$ & & \\
\hline Axillary tail & 12 & 1.62 & 109.175 & $65.910-152.440$ & & \\
\hline
\end{tabular}

Table 1 (continued) 
Table 1 (continued)

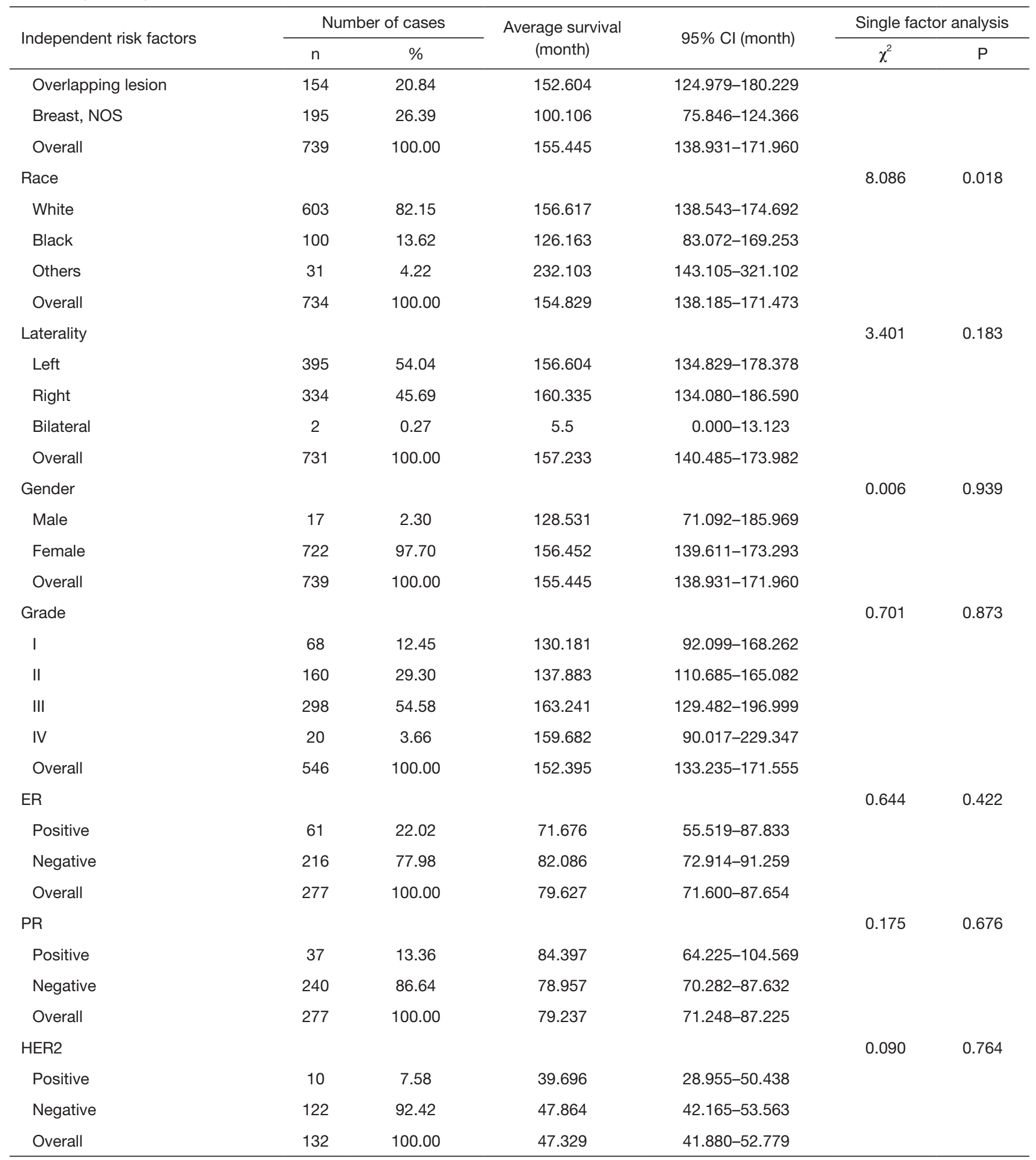

BSqCC, breast squamous cell carcinoma; ER, estrogen receptor; PR, progesterone receptor; HER2, human epidermal growth factor receptor 2 . 


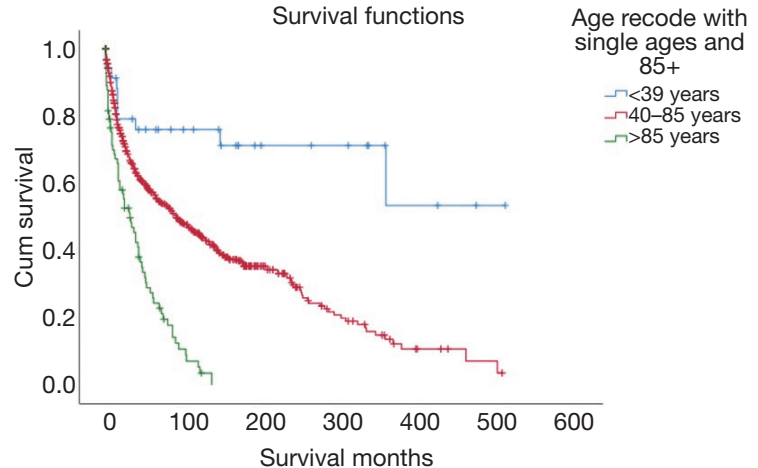

Figure 1 Kaplan-Meier survival curves of age.

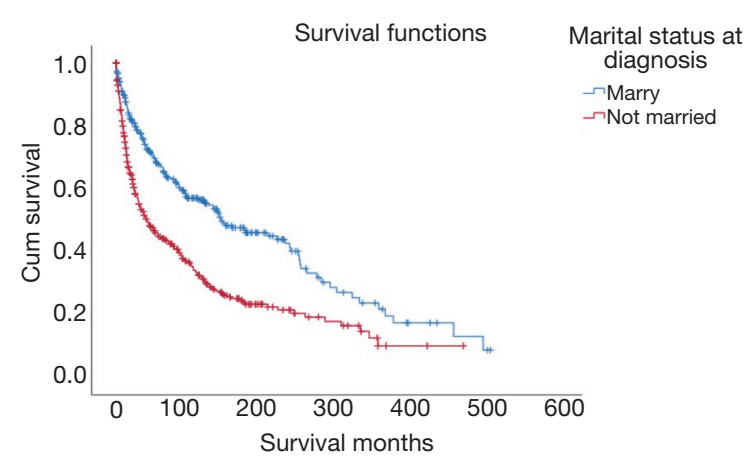

Figure 2 Kaplan-Meier survival curves of married status.

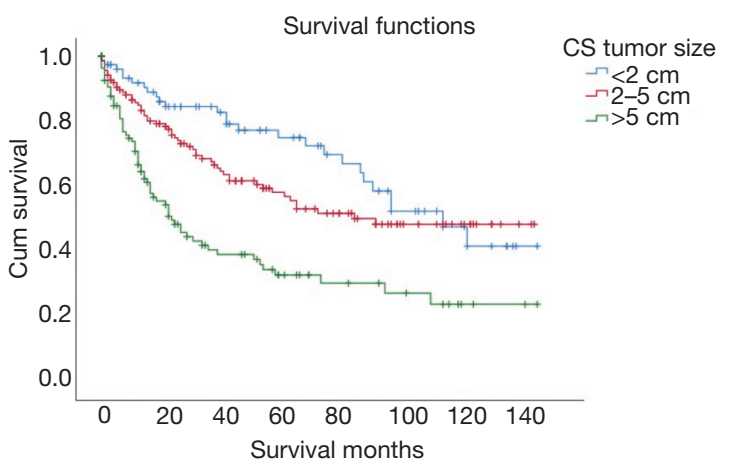

Figure 3 Kaplan-Meier survival curves of tumor size.

The calibration plots showed a correlation between observed OS and nomogram predicted OS (Figure 8).

\section{Discussion}

\section{Analysis of demographic results}

We used the SEER database to diagnose 739 patients

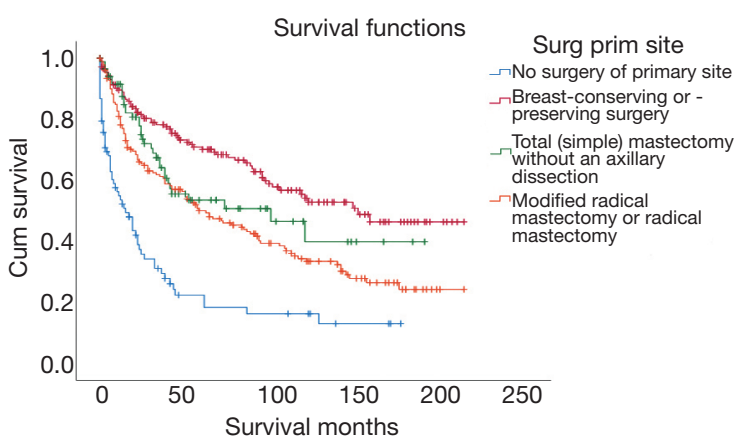

Figure 4 Kaplan-Meier survival curves of surgery.

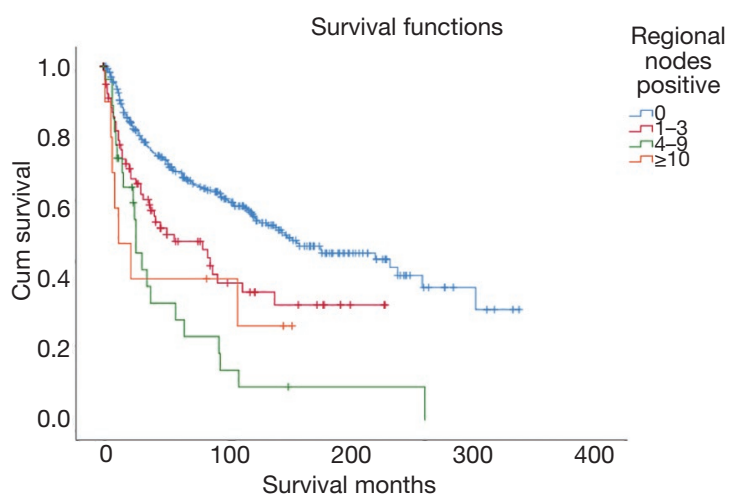

Figure 5 Kaplan-Meier survival curves of regional nodes positive.

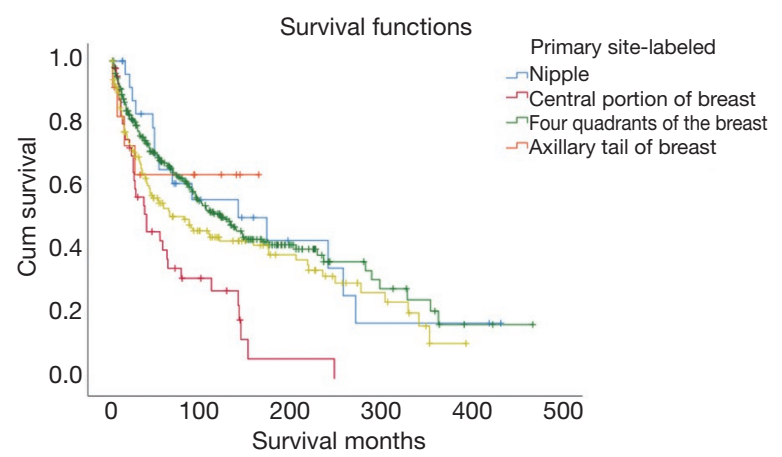

Figure 6 Kaplan-Meier survival curves of the primary site.

with BSqCC from 1973 to 2015, to explore the effect age, gender, race, marriage, tumor size, primary site, and surgical procedure on the prognosis of patients. This has been the most extensive study on BSqCC so far. Our study confirmed that breast SCC was a rare tumor, accounting for less than $0.1 \%$ of breast cancer. The difference between incidence of male and that of female was significant, and females accounted for $97.7 \%$. However, there was no statistically 
Table 2 COX regression analysis of independent risk factors

\begin{tabular}{llll}
\hline Independent risk factors & $\mathrm{HR}$ & $95 \% \mathrm{Cl}$ & $\mathrm{P}$ \\
\hline Marital status & 0.502 & $0.318-0.794$ & 0.003 \\
Age & 2.186 & $1.234-3.875$ & 0.007 \\
Surgery & 1.03 & $1.01-1.051$ & 0.003 \\
Tumor size & 1.505 & $1.083-2.091$ & 0.015 \\
Regional nodes positive & 1.277 & $1.087-1.499$ & 0.003 \\
\hline
\end{tabular}

Points
Age
Marital status
Tumor size
Surgery
No.nodes
Total points
1-year survival probablity
3-year survival probablity
10-year survival probablity

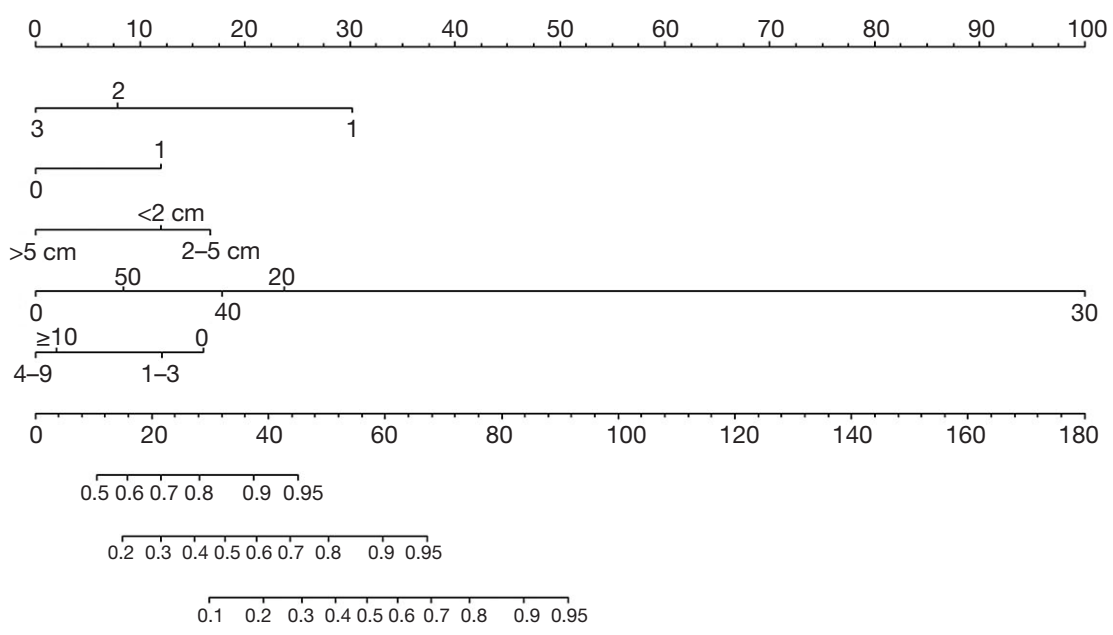

Figure 7 Nomogram for predicting 1-, 3-, and 10-year OS of BSqCC. BSqCC, breast squamous cell carcinoma.

significant difference between male and female in prognosis, which was different from the results of ordinary breast cancer, suggesting that we should knock gender off the screening criteria. Breast cancer had a significant race distribution difference (14). After removing the unrecorded cases, the whites accounted for $82.15 \%$, but the prognosis had no statistical difference. Our study divided patients into three groups by age, and 40 to 85 years old people accounted for the majority. Patients under the age of 40 had the longest survival, while prognosis of patients over 85 years old was worst, indicating that there was a statistical difference in the age of patients with BSqCC. Similar to breast cancer, there was a relationship between $\mathrm{BSqCC}$ and marital status. However, there had not been related research on etiology (15).

\section{The impact of imaging, laboratory and pathological examination on the prognosis of patients}

This study showed that among the explored risk factors, namely primary site, tumor size, number of positive lymph nodes, hemiplegic, histological classification, histological grade, ER, PR, HER2, only the primary site, tumor size, and positive lymph node number had a statistically impact on the prognosis of patients. The data showed that primary tumor site in the upper quadrant of the breast $(24.09 \%)$ was the most, and the survival time of primary tumor site in the upper quadrant was the longest (250.651 months), with statistical difference. Tumor size and lymph node involvement were the most important prognostic factors in the literature (16). In our study, this was very obvious, as the tumor volume increased, the patient's survival time was shortened, which was in line with our general perception. Lymph node involvement was also a factor of poor prognosis. Most patients had no positive lymph nodes (72\%), and their prognosis was better (average 180.936 months) than those of patients with positive lymph nodes. However, the average survival time of patients (57.18 months) with 4-9 positive lymph nodes was less than that of more than 

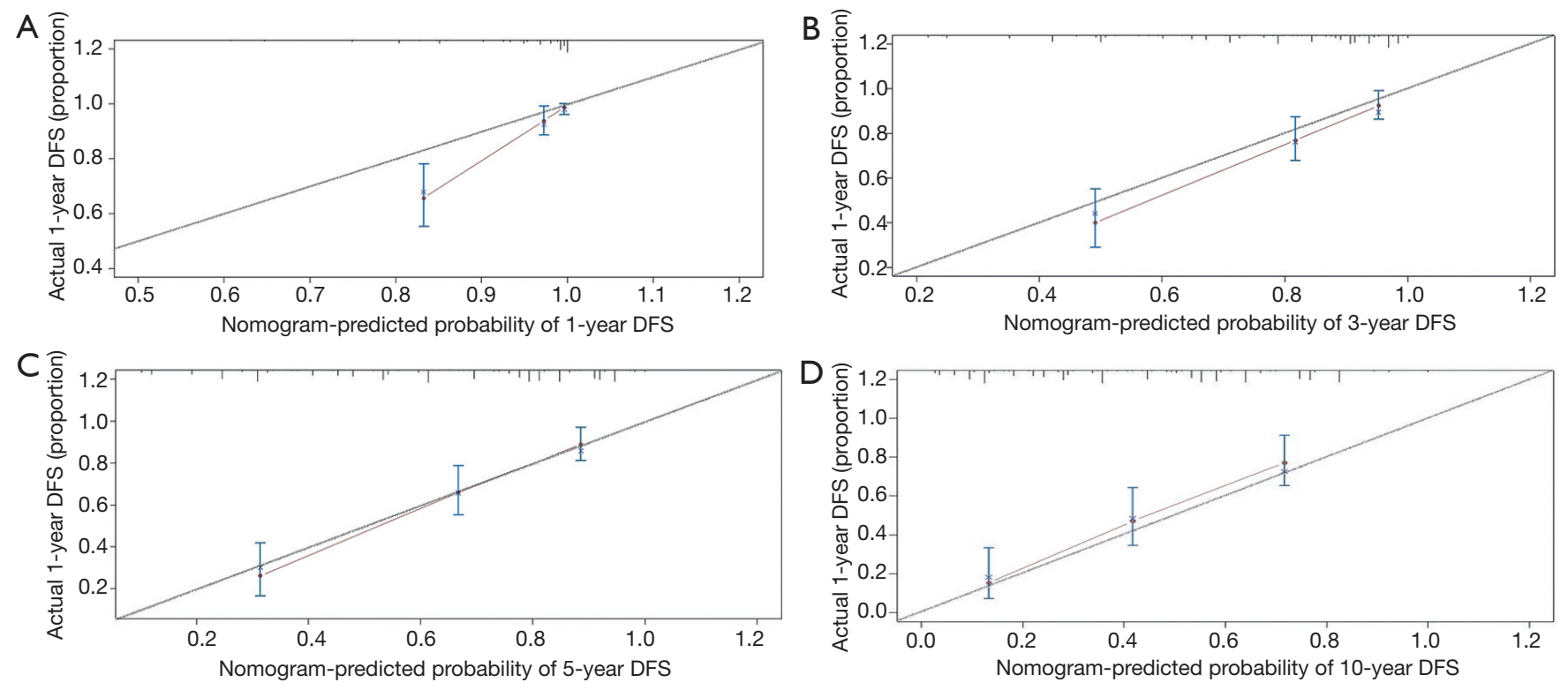

Figure 8 Nomogram model calibration curves.

10 (60.633 months), this might be the error caused by insufficient sample size.

\section{The effect of treatment on survival time of patients}

Due to its low incidence, the diagnosis, treatment, and evaluation of BSqCC were quite tricky. There was no standard treatment plan $(10,13)$, and surgery-based comprehensive treatment was usually used. Our study showed that the surgical procedure was an independent risk factor for patient survival, with statistically significant differences $(\mathrm{P}<0.001)$. The most common choice was radical or modified radical mastectomy (34.59\%), with an average survival time of 91.185 months, but the most prolonged prognostic survival (131.909 months) was found in patients with breast-conserving surgery, which may be due to the choice of breast-conserving surgery, or the possibility of routine radiotherapy after breast-conserving surgery, or better tumor conditions of these patients. ER, PR, and HER2 had no significant difference in prognosis, which was consistent with the insensitivity of $\mathrm{BSqCC}$ patients to endocrine therapy, Herceptin, and other targeted drugs (17). Cytogenetic techniques had been used to detect breast cancer with intratumorally heterogeneity (18), which undoubtedly increased the difficulty of its treatment. Given the strong invasiveness and refractory nature of $\mathrm{BSqCC}$, it had been suggested to use platinum-based chemotherapy, which was usually used for squamous cell tumors in other sites $(7,17,19)$. Recent reports indicated that eribulin in neoadjuvant chemotherapy could be used to treat women with pure $\mathrm{BSqCC}(20,21)$. Generally, $\mathrm{BSqCC}$ was sensitive to radiotherapy, but some cases had a recurrence in the radiotherapy area, suggesting that there might be relative anti-radiation (22).

\section{Study of prognosis survival rate}

Researchers believed that $\mathrm{BSqCC}$ was highly invasive and worse than the prognosis of typical triple-negative breast cancer (23). SATO's (24) research have shown that patients with $\mathrm{BSqCC}$ had a median overall disease-free survival of only 20 months; and the 5 -year disease-free survival rate was $26 \%$; the 5 -year median survival was 37 months; and the 5 -year overall survival rate was only $40 \%$. Another study of 11 patients with primary squamous cell carcinoma of the breast who were treated and followed up for 30 years reported a 5-year survival rate of $67 \%$ (25). Our study showed that the median survival time was 44 months; the 3 -year survival rate was $62.9 \%$; the 5 -year survival rate was $54.4 \%$; and the 10 -year survival rate was $41.4 \%$. The risk factors for prognosis survival in BSqCC patients included age, surgical procedure, number of positive lymph nodes, primary site, and tumor size. Basing on this, we developed a prognostic nomogram with excellent discrimination for 
breast cancer squamous cell carcinoma, which could help clinicians make decisions on a personal basis.

\section{Insufficient and limited}

Our research also had some limitations. Although the sample size of this report has been the largest so far, 739 cases were still not enough. Some subgroups had a small sample size, and part of the follow-up data was seriously missing. For example, there were only 10 patients with HER2 positive. Most of the patients diagnosed before $2010 \mathrm{did}$ not have immunohistochemical data, so only 133 of these partial cases were complete. We would continue to follow up on the data and update the research.

\section{Acknowledgments}

Funding: This work was supported by the National Natural Science Foundation of China, Youth Fund [grant number: 8170102526], and Undergraduate Innovation Practice Capability Incubation Base of China, Navy Medical University [grant number: FH2018224].

\section{Footnote}

Conflicts of Interest: All authors have completed the ICMJE uniform disclosure form (available at http://dx.doi. org/10.21037/tcr.2019.09.13). The authors have no conflicts of interest to declare.

Ethical Statement: The authors are accountable for all aspects of the work in ensuring that questions related to the accuracy or integrity of any part of the work are appropriately investigated and resolved. This study was conducted in accordance with the Declaration of Helsinki (as revised in 2013). Since any information in the SEER database does not require the patient's explicit consent, it is not subject to the ethical approval requirements of the institutional review board.

Open Access Statement: This is an Open Access article distributed in accordance with the Creative Commons Attribution-NonCommercial-NoDerivs 4.0 International License (CC BY-NC-ND 4.0), which permits the noncommercial replication and distribution of the article with the strict proviso that no changes or edits are made and the original work is properly cited (including links to both the formal publication through the relevant DOI and the license).
See: https://creativecommons.org/licenses/by-nc-nd/4.0/.

\section{References}

1. Gupta N, Vashisht R, Nimbran V, et al. Primary squamous cell carcinoma of the breast: case report and management decisions. J Cancer Res Ther 2012;8:323-5.

2. Tan YM, Yeo A, Chia KH, et al. Breast abscess as the initial presentation of squamous cell carcinoma of the breast. Eur J Surg Oncol. 2002;28:91-3.

3. Nozoe T, Mori E, Ninomiya M, et al. Squamous cell carcinoma of the breast. Breast Cancer. 2012;19:177-9.

4. Liu J, Yu Y, Sun JY, et al. Clinicopathologic characteristics and prognosis of primary squamous cell carcinoma of the breast. Breast Cancer Res Treat. 2015;149:133-40.

5. Badge SA, Gangane NM, Shivkumar VB, et al. Primary squamous cell carcinoma of the breast. Int J Appl Basic Med Res 2014;4:53-5.

6. Hennessy BT, Krishnamurthy S, Giordano S, et al. Squamous cell carcinoma of the breast. J Clin Oncol 2005;23:7827-35.

7. Behranwala KA, Nasiri N, Abdullah N, et al. Squamous cell carcinoma of the breast: clinicopathologic implications and outcome. Eur J Surg Oncol 2003;29:386-9.

8. Yadav S, Yadav D, Zakalik D. Squamous cell carcinoma of the breast in the United States: incidence, demographics, tumor characteristics, and survival. Breast Cancer Res Treat 2017;164:201-8.

9. Ishikawa N, Saimura M, Koga K, Anan K, et al. A Case of Metaplastic Squamous Cell Carcinoma of the Breast Diagnosed after Neoadjuvant Chemotherapy. Gan To Kagaku Ryoho 2018;45:1101-3.

10. Alan O, Telli TA, Ercelep O, et al. A case of primary squamous cell carcinoma of the breast with pathologic complete response after neoadjuvant chemotherapy. Curr Probl Cancer 2019;43:308-11.

11. Cha N, Wang S, Lv M, et al. Breast Metaplastic Squamous Cell Carcinoma Diagnosed with Fine Needle and Core Biopsy: A Case Study. Am J Case Rep 2018;19:203-6.

12. Jakubowska K, Kanczuga-Koda L, Kisielewski W, et al. Squamous cell carcinoma of the breast as a clinical diagnostic challenge. Mol Clin Oncol. 2018;8:587-91.

13. Aparicio I, Martinez A, Hernandez G, et al. Squamous cell carcinoma of the breast. Eur J Obstet Gynecol Reprod Biol 2008;137:222-6.

14. Iqbal J, Ginsburg O, Rochon PA, et al. Differences in breast cancer stage at diagnosis and cancer-specific 
survival by race and ethnicity in the United States. JAMA 2015;313:165-73.

15. Hinyard L, Wirth LS, Clancy JM, et al. The effect of marital status on breast cancer-related outcomes in women under 65: A SEER database analysis. Breast 2017;32:13-7.

16. Tayeb K, Saadi I, Kharmash M, et al. Primary squamous cell carcinoma of the breast. Report of three cases. Cancer Radiother 2002;6:366-8.

17. Tsung SH. Primary pure squamous cell carcinoma of the breast might be sensitive to Cisplatin-based chemotherapy. Case Rep Oncol 2012;5:561-5.

18. Oikawa M, Igawa A, Taguchi K, et al. Cytogenetic analysis of metaplastic squamous cell carcinoma of the breast inter- and intratumoral heterogeneity. Breast Cancer 2017;24:733-41.

19. Hiramatsu K, Kato K, Hirata A, et al. A resected case of squamous cell carcinoma of the breast successfully treated by FU plus cisplatin (CDDP) adjuvant therapy against recurrent metastases. Gan To Kagaku Ryoho 2007;34:443-6.

20. Kashiwagi S, Okuno T, Ishihara S, et al. Effectiveness of

Cite this article as: Cheng Z, Han T, Zhang X, Li X, Li H, Gu J. Prognostic factors for breast cancer squamous cell carcinoma and nomogram development for prediction: population-based research. Transl Cancer Res 2019;8(5):2014-2023. doi: 10.21037/ tcr.2019.09.13 eribulin chemotherapy for squamous cell carcinoma of the breast. Gan To Kagaku Ryoho 2013;40:2369-71.

21. Goto Y, Yoshida T, Kimura M. Higher efficacy and complete response with administration of eribulin for recurrent squamous cell breast carcinoma: A case report. Mol Clin Oncol 2018;9:318-20.

22. Damin AP, Nascimento FC, Andreola JB, et al. Primary epidermoid carcinoma of the breast presenting as a breast abscess and sepsis. Sao Paulo Med J 2011;129:424-7.

23. Benoist P, Mureau A, Joueidi Y, et al. Management and prognosis of pure primary squamous cell carcinoma of the breast. J Gynecol Obstet Hum Reprod 2018;47:275-80.

24. Sato Y, Inatome J, Okishiro M, et al. A Case of Pure Squamous Cell Carcinoma of the Breast in an Elderly Woman Diagnosed by Cytology. Gan To Kagaku Ryoho 2016;43:2259-61.

25. Punzo C, Fortarezza F, De Ruvo V, et al. Primitive squamous cell carcinoma of the breast (SCCB): case report of an uncommon variant of metaplastic carcinoma. G Chir 2017;38:139-42. 